\title{
Simultaneous measurement of aerodynamic and heat transfer data for large angle blunt cones in hypersonic shock tunnel
}

\author{
NIRANJAN SAHOO ${ }^{1, *}$, S SARAVANAN $^{2}$, G JAGADEESH $^{2}$ and \\ K P J REDDY ${ }^{2}$ \\ ${ }^{1}$ Department of Mechanical Engineering, Indian Institute of Technology, \\ Guwahati 781 039, India \\ ${ }^{2}$ Department of Aerospace Engineering, Indian Institute of Science, \\ Bangalore 560 012, India \\ e-mail: shock@iitg.ernet.in
}

MS received 9 May 2005; revised 27 February 2006

\begin{abstract}
Aerodynamic forces and fore-body convective surface heat transfer rates over a $60^{\circ}$ apex-angle blunt cone have been simultaneously measured at a nominal Mach number of 5.75 in the hypersonic shock tunnel HST2. An aluminum model incorporating a three-component accelerometer-based balance system for measuring the aerodynamic forces and an array of platinum thin-film gauges deposited on thermally insulating backing material flush mounted on the model surface is used for convective surface heat transfer measurement in the investigations. The measured value of the drag coefficient varies by about $\pm 6 \%$ from the theoretically estimated value based on the modified Newtonian theory, while the axi-symmetric Navier-Stokes computations overpredict the drag coefficient by about $9 \%$. The normalized values of measured heat transfer rates at $0^{\circ}$ angle of attack are about $11 \%$ higher than the theoretically estimated values. The aerodynamic and the heat transfer data presented here are very valuable for the validation of CFD codes used for the numerical computation of flow fields around hypersonic vehicles.
\end{abstract}

Keywords. Aerodynamic and heat transfer data; large angle blunt cone; hypersonic flow shock tunnel.

\section{Introduction}

Hypersonic research activities around the globe has been in major focus in recent times because of the milestone developments in hypersonic reentry vehicles, orbital transfer vehicles, reusable launch vehicles and space recovery experimental modules. While atmospheric re-entry vehicles have been flown successfully by both USA and the erstwhile Soviet Union,

\footnotetext{
*Corresponding author
} 
the recent failure of the Columbia Space Shuttle during re-entry bears testimony to the fact that there are still a few grey areas which require considerable research endeavours before hypersonic space missions become a part of commercial aviation industry. Severe aerodynamic heating during re-entry, difficulties in attitude/stability control during re-entry, lack of precise information on the requisite thermal protection system (TPS) for the vehicle and associated structural constraints are some of the impediments in the design of hypersonic vehicles. With the tremendous progress in computational powers in recent times, computational fluid dynamics (CFD) tools are increasingly being used in most aerodynamic designs even in the hypersonic flight corridors. Concurrently, careful experiments in ground-based test facilities continue to play an important role in providing vital design data as well as insight into the unknown aspects of flow physics. However, more reliable, innovative and carefully designed experimental techniques/methodologies are needed for the generation of data for CFD code validation, especially at hypersonic Mach numbers.

Vehicles with high lift to drag ratio, in the usual paradigm are not considered in hypersonic flight corridors since convective heating to the relatively sharp edges produces unacceptably high heating loads. Hence, in most inter-planetary space missions, large angle blunt cones (semi-apex angle $30^{\circ}-70^{\circ}$ ) with low lift-to-drag ratios are employed (Peter \& Donn 1987; Stewart \& Chen 1994; Brian \& John 1997). The high wave drag associated with such bodies is immensely useful in aero-braking and aero-capture space maneuvers. Aerodynamic heating and generation of aerodynamic forces over bodies travelling at hypersonic Mach numbers are complimentary phenomena. Generally, aerodynamic heating increases as the cube of the velocity while wave drag increases as the square of the velocity. Hence, at hypersonic speeds precise information on both wave drag and surface heat transfer rates are essential in deciding on both the requisite TPS and vehicle/capsule stability margins during flight. Usually the information on the surface heat transfer rates and the basic aerodynamic drag coefficients is obtained from careful experiments in the ground-based test facilities, which is then complemented by CFD studies.

Hypersonic shock tunnels/free piston-driven shock tunnels are the most useful impulse ground test facilities that are capable of simulating the total energy content of the flow in addition to Mach and Reynolds numbers in the hypersonic flow regime. However, one of the major limitations of these impulse facilities is the ultra-short test time, which typically ranges from 0.5 to $2 \mathrm{~ms}$. Owing to the inherent constraints in the existing measurement methodologies/techniques, usually different scale models are used for aerodynamic drag and heat transfer measurements in hypersonic flow experiments. This approach has been used with reasonable success in long duration test facilities like hypersonic wind tunnels where the reservoir conditions can be easily controlled during experiments. On the other hand, in short duration impulse facilities like shock/free piston driven shock tunnels, reservoir conditions are obtained by shock compression in the driven section of the shock tube. The shot to shot variation in the freestream conditions in test section can range anywhere from \pm 5 to $\pm 15 \%$. Moreover, it is very difficult to ensure an identical test flow spectrum over the test model in every run in shock tunnel facilities. Also, in some tunnels where the test section size is smaller because of the blockage effects, it may not be possible to mount a model beyond a certain size and in most force measurement experiments it is the force balance which dictates the size of the model in tunnel testing. In addition, carrying out separate tests for force and heat transfer measurements is quite expensive. The cumulative effect essentially results in varying degrees of uncertainties in the measured values of drag and heat transfer rates at almost identical test flow conditions for a given model. Hence, this type of data will lead to erroneous conclusions when used for validating CFD codes. Therefore, it is certainly desirable to enhance the fidelity 
of the measured values of aerodynamic drag coefficients and convective surface heat transfer rates for large angle blunt cones that are routinely used for validating CFD codes used in hypersonic re-entry vehicle design studies.

In order to eliminate the problems highlighted above, we present in this paper a novel method of measuring both aerodynamic forces and surface heat transfer rates simultaneously. The technique is used to measure aerodynamic as well as heat transfer data simultaneously for a $60^{\circ}$ apex-angle blunt cone flying at Mach 5.75 in the IISc (Indian Institude of Science) hypersonic shock tunnel HST2. Over the years, several different types of aerodynamic force balance systems developed for shock tunnel applications have been reported in the open literature (Joshi \& Reddy 1986; Jessan \& Gronig 1989; Raju \& Reddy 1990; Naumann et al 1993; Mee et al 1996). Here, the aerodynamic forces on the blunt cone are measured using a three-component accelerometer balance system (Sahoo et al 2002, 2003) and the surface heat transfer rates are measured using platinum thin-film thermal sensors (Jagadeesh et al 2000). The blunt cone model is designed such that it accommodates an internal three-component accelerometer-based force balance system as well as thermally insulating ceramic glass Macor substrate over which platinum thin film sensors are deposited. The three-component balance system is calibrated by comparing the numerically estimated axial direction acceleration levels with the experimentally measured values. The problems associated with inserting a Macor substrate of suitable thickness in the metallic blunt cone model in presence of an internally mounted force balance system are certainly not trivial. For accurately measuring the surface heat transfer rates the platinum thin film sensors should be deposited on a ceramic substrate with a certain minimum thickness so that during the short test time there is no heat conduction through the substrate. This minimum thickness of the ceramic substrate depends on the steady test time in the tunnel and its thermal diffusivity. In subsequent sections, the details of the experiments, drag and heat transfer measurement methodologies, important experimental results along with the corresponding results from the finite element method (FEM) and CFD studies are discussed. The experimental data presented in this paper are expected to be very valuable for the validation of CFD codes used for computing the flow fields around flight vehicles in cold hypersonic flow environments.

\section{Experimental facility}

The HST2 hypersonic shock tunnel is schematically shown in figure 1 . The shock tube portion of the tunnel consists of a $50 \mathrm{~mm}$ inner diameter stainless steel driver and driven sections separated by a metal diaphragm. Platinum thin film sensors located towards the end of the driven section monitor the shock wave velocity. The pressure jump across the shock wave is measured using a pressure transducer (PCB, Piezotronics) located at the end of the driven section. The wind tunnel portion of the HST2 comprises a truncated conical nozzle terminating into a $30 \times 30 \mathrm{~cm}$ size test section. The typical test conditions of the experiments are shown in table 1 . The tunnel is capable of producing a reservoir enthalpy of up to $5 \mathrm{MJ} / \mathrm{kg}$ and has an effective test time of about $800 \mu \mathrm{s}$. A transient PC-based data acquisition system with requisite software is used for recording and processing the data.

\section{Design methodology of the test model for simultaneous measurement}

Design and fabrication of the blunt cone test model for simultaneous measurement of aerodynamic forces and convective heating rates in the shock tunnel are influenced to a large extent 


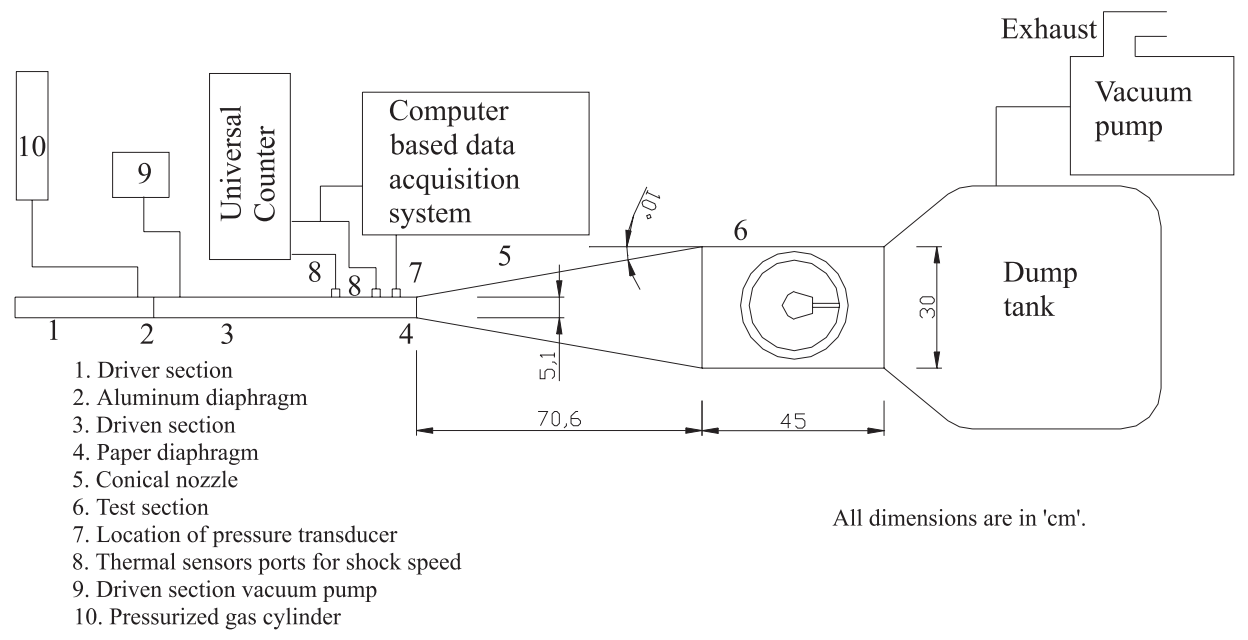

Figure 1. Schematic diagram of the IISc hypersonic shock tunnel HST2.

by the techniques adopted for the measurement and model-mounting mechanism in the tunnel. In addition, the following technical factors need to be considered while fixing the size of the test model for simultaneous measurement study.

(a) Effects of tunnel wall boundary layer and blockage factor;

(b) effects of model, balance and support systems on force measurements;

(c) effects of substrate thickness of platinum sensors on heating rate measurements;

(d) freestream Reynolds number effects on flow behaviour.

\subsection{Effects of tunnel wall boundary layer and blockage factor}

One major factor that imposes the limiting criterion on the size of the model that can be tested in the hypersonic flow is the tunnel wall boundary layer and blockage factor. For hypersonic flow, the boundary layer thickness $(\delta)$ can be correlated to the freestream Mach number $\left(\mathrm{M}_{\infty}\right)$ and Reynolds number $\left(\operatorname{Re}_{\infty}\right)$ as,

$$
\delta / X \alpha M_{\infty}^{2} /\left(\operatorname{Re}_{\infty}\right)^{1 / 2},
$$

where $X$ is the length of the test section. Hence, the hypersonic boundary layers are orders of magnitude thicker than low speed boundary layers for the same Reynolds number (Anderson 1989). In fact, the thick boundary layer of the hypersonic flow exerts a major displacement effects on the inviscid flow outside the boundary layer.

The maximum model dimensions that can be accommodated in a tunnel are essentially dictated by the test section blockage factor. The blockage factor is defined by the ratio of the plan form area of the model exposed to the flow to the maximum area available for the flow. It is necessary that the hypersonic jet coming out of the nozzle should not be affected by the blockage parameters. In most of the shock tunnel applications, the maximum size of the model is limited to one-third of the test-section dimension. 
Based on the above principle, the maximum lateral dimension of the test model is limited to $70 \mathrm{~mm}$ for the HST2 shock tunnel and thereby ensures placement of the model in the inviscid core even at higher angles of attack (up to $15^{\circ}$ ).

\subsection{Effects of model, balance and support systems on force measurements}

In designing the blunt cone test model, we must know the expected force that will act on the models when exposed to hypersonic flow. Based on the expected load, the material for the modal can be chosen. It is imperative to note that larger mass leads to lower signal-to-noise ratio and vice versa. Hence, to be on a safer side, light metals may be considered for model fabrication for higher signal-to-noise ratios. Accordingly, the present test model is fabricated with an aluminum alloy for reducing weight. The model size is such that it can house the threecomponent accelerometer balance system to measure aerodynamic forces. The free flying condition of the model is achieved by suspending the model using flexible rubber bushes. Other design details of the accelerometer balance system are presented in subsequent sections.

\subsection{Effect of substrate thickness of platinum sensors on heating rate measurements}

The use of platinum thin-film sensors for measuring surface convective heat transfer rates at hypersonic Mach numbers is well known (Schultz \& Jones 1973; Hollis 1995). When we measure heat transfer rates for a given test model, it is very important to ensure a minimum thickness of Macor so that the classical 1-D semi-infinite slab heat transfer model usually used for calculating the surface heat transfer rates is valid. For the sake of completion, some of the details of the basic theory of heat transfer measurements are briefly discussed in this section.

For accurate heating rate measurements, it is necessary that heat should not be conducted into the model during the experiments. It would be ideal if the complete model were made of thermally insulating substrate/backing material. The sensors are typically designed such that the thickness of the sensing element is much less than that of substrate. Hence, the sensing element has almost negligible effect on the heat transfer rate to the substrate and the temperature measured by the sensing element is identical to that at the surface of the substrate.

The generic surface temperature sensor mounted on a substrate material is schematically shown in figure 2. The 1-D convective heat transfer analysis for this scenario can be carried out based on the following assumptions: (a) the temperature measured by the sensing element is identical to that of the substrate; (b) there is no lateral heat conduction through the substrate and the heat is conducted only in the direction normal to the surface; (c) the substrate is of infinite depth, and the temperature rise at infinity is zero; (d) the thermal properties of the substrate are constant. Using this model the temperature distribution along the depth of the substrate can be written as:

$$
\partial^{2} T / \partial x^{2}=(1 / \alpha)(\partial T / \partial t)
$$

The boundary conditions are given by

$$
\begin{aligned}
T\left(x, t=t_{o}\right) & =T_{o}, \\
T(x=0, t) & =T_{s}(t), \\
\dot{q}(x=\infty, t) & =0,
\end{aligned}
$$

where $T(x)$ is the temperature at any location $x, T_{s}$ is the surface temperature, $\dot{q}$ is the heat transfer rate and $\alpha=\left(k / \rho C_{p}\right)$ is the thermal diffusivity of the substrate. 


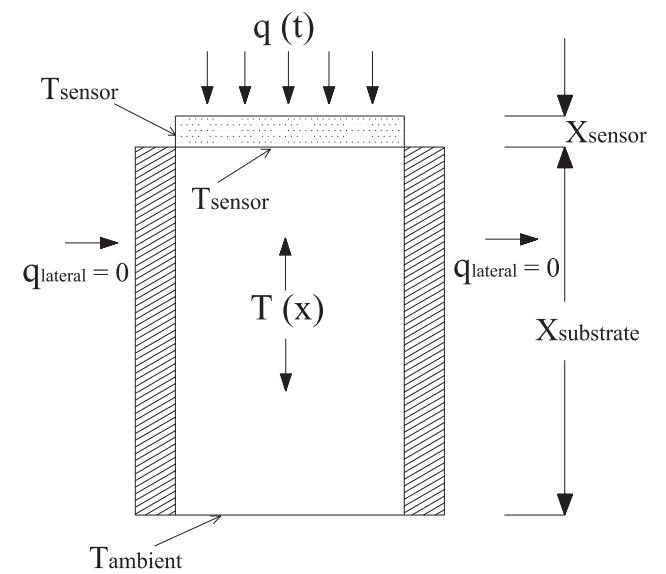

Figure 2. Schematic representation of the 1-D heat conduction model of the platinum thin-film resistance sensors used for measuring the heat transfer rates.

The validity of the semi-infinite substrate assumption depends on the material depth, diffusivity and test duration and these can be expressed in terms of the increase in the temperature or heat transfer rate at the back of the substrate (Hollis 1995). Hence, there exists a nondimensional length that relates the thermal penetration depth, thermal diffusivity and useful test time. This is given in the form,

$$
x^{*}=x /(2 \sqrt{\alpha t}) .
$$

Since the penetration depth is inversely proportional to the square root of diffusivity, materials with lower diffusivity (such as ceramics) have longer semi-infinite test time, whereas high diffusivity materials (such as metals) have shorter semi-infinite test time. Equation (2) along with the boundary conditions can be solved to obtain the back face heat transfer rate and temperature for a constant heating rate. The solutions for (2) can be expressed in terms of $x^{*}$ as;

$$
\begin{aligned}
& T_{x} / T_{s}=\exp ^{\left(-x^{*}\right)^{2}}-\left(x^{*} \sqrt{\pi}\right) \operatorname{erfc}\left(x^{*}\right) \\
& \dot{q}_{x} / \dot{q}_{s}=\operatorname{erfc}\left(x^{*}\right)
\end{aligned}
$$

Equations (5) and (6) plotted in terms of the non-dimensional length $x^{*}$ are shown in figure 3. Ideally, the substrate should be thick enough such that the ratio $\left(\dot{q}_{x} / \dot{q}_{s}\right)$ at the back face of the substrate is no more than a few percent for the test time desired. From (5) and (6) and figure 3, the optimum thickness for an ideal insulative substrate $\left[\left(\dot{q}_{x} / \dot{q}_{s}\right) \sim 0\right]$ for a known test time can be obtained by choosing a very high value of $x^{*}$.

For the heat transfer measurements based on this thin-film technique, the typical substrate and sensing material are usually Macor $\left(\alpha=7.94 \times 10^{-7} \mathrm{~m}^{2} / \mathrm{s}\right)$ and platinum respectively. Macor possesses very good machinability and at the same time is extremely hard and brittle. For the present set of experiments in hypersonic shock tunnel HST2, we decided to fabricate the model using special aluminum alloy, with a strip of Macor insert to act as the insulating base substrate for thin-film deposition. The required thickness of Macor can be decided based on available test time for the shock tunnel using (4). Figure 4 shows the variation of the Macor thickness $(x)$ with the test time $(t)$ for a given non-dimensional length $\left(x^{*}\right)$. For instance, the effective test time in HST2 is $800 \mu$ s. With this test time, different values of $x^{*}$ can be chosen. For lower value of $x^{*}$, the desired thickness of Macor is too small and hence may lead to a mounting problem on the model surface. Hence, the thickness of Macor is decided by the 


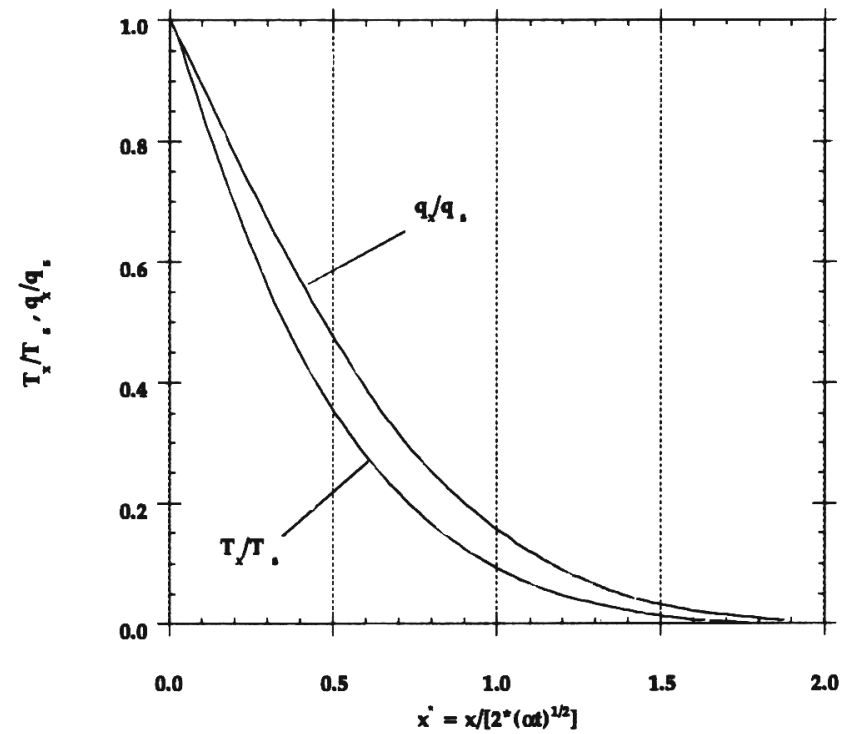

Figure 3. Variation of heating rates along the depth of the substrate as a function of $x^{*}$ (Hollis 1995).

available thickness on the model surface. In the present experiments, for test time of $800 \mu \mathrm{s}$, $x^{*}$ is chosen to be 100 and the corresponding Macor thickness is $5 \mathrm{~mm}$ (figure 4). Finally, a single strip of $16 \mathrm{~mm}$ width and $5 \mathrm{~mm}$ thick Macor is fixed along the diametrical ray, flush with the aluminum model.

\subsection{Freestream Reynolds number effects on flow behaviour}

Boundary layers at hypersonic speeds are relatively thick and more prone to separation in the presence of unfavorable pressure gradients than at supersonic speeds. Also, there are likely to be important interactions between shock waves and boundary layers. Under these conditions, loads on the model can no longer be considered simply as those due to inviscid flow field, which exerts pressures through the boundary layer and onto the model surface. Normally, the

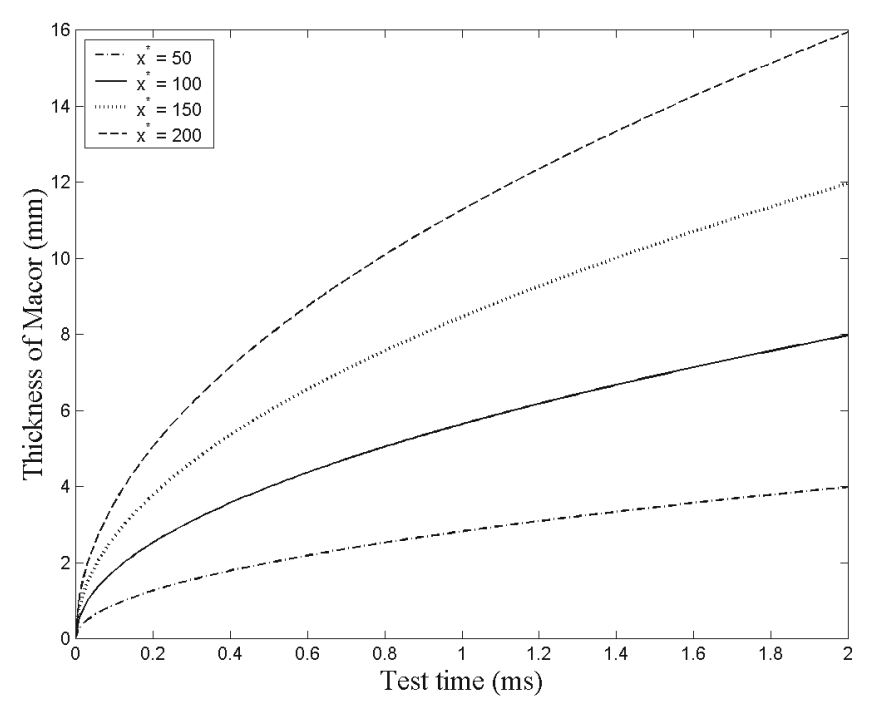

Figure 4. Variation of the thickness of Macor insulator as a function of hypersonic shock tunnel test times. 
boundary layers on the models in the hypersonic tunnels are laminar and primarily depend on the Reynolds number based on model dimension. It is worthwhile mentioning that boundary layer is the answer to the problem of obtaining comparable flow fields over the model in the tunnel and full-scale vehicle in flight. In flight at hypersonic speeds, a full-scale vehicle is likely to have long runs of laminar flow if it has reasonably smooth surfaces. The reported literature suggests that even during actual rocket testing, when the Reynolds number was $\sim 70 \times 10^{6}$ there was no transition from laminar to turbulent flow (Alan \& Kennith 1965). Therefore, the general practice at present is to make the model surface sufficiently smooth so as to avoid transition.

\section{Test model and instrumentation}

In summary, the test model size in the shock tunnel essentially depends on the type of nozzle (conical or contoured), the size of the hypersonic jet issuing out of the nozzle (depends on exit diameter of the nozzle) and the size of the test section $(300 \times 300 \times 450 \mathrm{~mm}$ length $)$. Although the theoretically estimated typical boundary layer thickness in the nozzle for the nominal Mach number and freestream unit Reynolds number is $\sim 12 \mathrm{~mm}$, as a conservative approach in HST2 testing, the model size is seldom over $100 \mathrm{~mm}$. Thus the model is invariably within the inviscid core of the hypersonic jet coming out of the nozzle, thereby avoiding blockage problems and possible interaction of the tunnel wall boundary layer with the aerodynamic flow field of the blunt cone during testing. In addition, it is also necessary to calculate the flow length (i.e. length of the flow passing over the model for the given model length) during which the measured aerodynamic parameters reach $98 \%$ of the final steady state values (Lee \& Lewis 1993; Abdel et al 2001). As a general approach, the flow length is typically 3 to 4 for attached flow and varies from 20 to 50 for flows with separated regions. In the present experiments, the $60^{\circ}$ apex-angle blunt cone model has the base diameter of $70 \mathrm{~mm}$ and bluntness ratio (defined as the ratio of nose diameter to the base diameter) of 0.857 . This model has essentially two parts, fore-body (consisting of spherical blunt nose and conical frustum) having a length of $30 \mathrm{~mm}$ and aft body (stepped-down skirt) with a length of $45 \mathrm{~mm}$. The fore-body portion of the blunt cone model is essentially useful in re-entry missions in order to reduce high heating load. Moreover, the high wave drag associated with such bodies is useful for aero-braking and aero-capture space maneuvers. Hence, simultaneous measurement of force and convective surface heating rates is intended only for the fore-body part. The dimensions of the fore-body part are sufficient to insert suitably thick Macor strips for depositing platinum thin-film sensors whereas the aft body accommodates the miniature accelerometer balance support system. Prior to shock tunnel experiments, aerodynamic force coefficients are estimated theoretically (Truitt 1959) for such composite body configurations. These preliminary investigations suggest that the stepped-down skirt does not contribute much to the drag even at angles of attack up to $15^{\circ}$. Though the total length of the model is $75 \mathrm{~mm}$, the fore-body length (excluding stepped-down aft body) of the model is only $30 \mathrm{~mm}$. Based on this analogy, the flow length corresponding to test conditions (table 1) vary from 25 to 40 for a test domain of $800 \mu \mathrm{s}$. These flow lengths are sufficient to reduce aerodynamic data even for the case with attached flow situations. A schematic diagram of the instrumented model along with the internally mounted accelerometer balance system is shown in figure 5 . The test model is fabricated with special lightweight aluminum alloy and mass of the model is $0.33 \mathrm{~kg}$. Miniature (12 mm height and $7 \mathrm{~mm}$ diameter) piezoelectric accelerometers (M303A PCB Piezotronics, USA) with a frequency bandwidth and sensitivity of $10 \mathrm{kHz}$ and $1.02 \mathrm{mV} / \mathrm{m} . \mathrm{s}^{-2}$ 


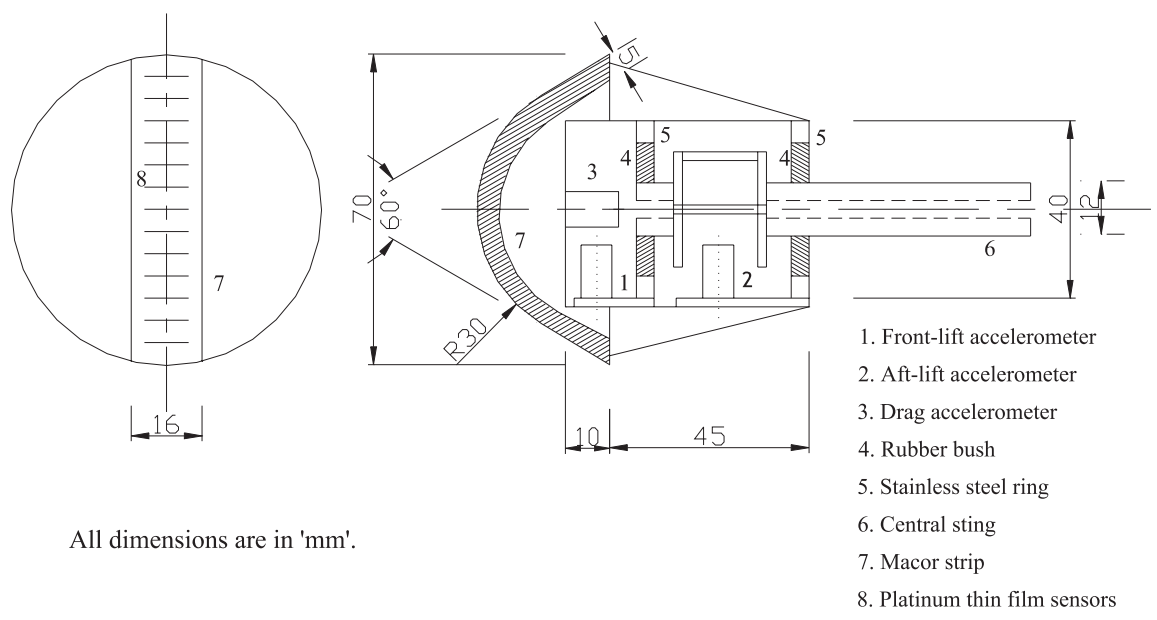

Figure 5. Schematic diagram of a $60^{\circ}$ apex-angle blunt cone model fitted with a three-component accelerometer balance system and platinum thin-film gauges for simultaneous measurement of aerodynamic forces and heat transfer rates.

respectively, are used for measuring the accelerations of the model in the test section. As general practice, the model surface is sufficiently smoothened so as to avoid transition. In fact, in the entire set of test conditions, the freestream unit Reynolds number is in the range of $1.2 \times 10^{6}-1.7 \times 10^{6}$ and hence doesn't lead to transition during testing. Hence, the flow is still laminar for the fore-body part of the model. The details of the methodology used in the measurement of aerodynamic force coefficients and heat transfer rates are presented in the following section.

Table 1. Nominal test conditions in IISc shock tunnel HST2*.

\begin{tabular}{lccc}
\hline \multicolumn{4}{c}{ Test gas: Air @ STP } \\
\hline Driver gas & Nitrogen & Helium & Helium \\
\hline Primary diaphragm thickness $(\mathrm{mm})$ & 1 & 1 & $1 \cdot 5$ \\
Shock Mach number, $M_{s}( \pm 2 \cdot 5 \%)$ & $2 \cdot 1$ & $3 \cdot 1$ & $3 \cdot 6$ \\
Stagnation pressure, $P_{0}(\mathrm{kPa})( \pm 8 \%)$ & $220 \cdot 0$ & $540 \cdot 0$ & $990 \cdot 0$ \\
Stagnation enthalpy, $H_{0}(\mathrm{MJ} / \mathrm{kg})( \pm 10 \%)$ & $0 \cdot 72$ & $1 \cdot 16$ & $1 \cdot 6$ \\
Freestream Mach number, $M_{\infty}( \pm 2 \%)$ & $5 \cdot 75$ & $5 \cdot 75$ & $5 \cdot 75$ \\
Freestream static pressure, $P_{\infty}(\mathrm{kPa})( \pm 5 \%)$ & $0 \cdot 18$ & 0.45 & 0.85 \\
Freestream static temperature, $T_{\infty}(\mathrm{K})( \pm 9 \%)$ & $95 \cdot 0$ & 140.0 & $210 \cdot 0$ \\
Freestream unit Reynolds number, $\mathrm{Re}\left(\mathrm{m}^{-1}\right)( \pm 16 \%)$ & $1 \cdot 2 \times 10^{6}$ & $1.4 \times 10^{6}$ & $1.6 \times 10^{6}$ \\
\hline
\end{tabular}

*The numbers inside the brackets indicate the percentage in uncertainties. 


\subsection{Measurement of aerodynamic forces for test model}

In the present investigation, a $60^{\circ}$ apex-angle blunt cone model with base diameter of $70 \mathrm{~mm}$ and bluntness ratio of $0 \cdot 857$, as shown in figure 5 , is chosen for the measurement of aerodynamic forces and heat transfer rates. Before the force measurement study was undertaken, some preliminary theoretical studies were carried out in order to find the expected aerodynamic loads on such bodies, when experiencing the freestream hypersonic flow conditions produced in the HST2 shock tunnel. These investigations suggest that such body geometries do not produce any lifts even at high angles of attack. Hence, although a threecomponent accelerometer balance system (Sahoo et al 2002, 2003) has been used in the present study, we have been able to measure only axial force due to the hypersonic flow over the model.

\subsection{Accelerometer balance system}

The force balance system is fabricated using non-magnetic stainless steel (SS304) material and the circular cross-section of the balance can be easily housed inside hollow portion of the blunt cone model. The balance comprises two annular rubber bushes adhesively bonded with outer annular steel rings as well as with a fastening central steel sting, which is rigidly fixed during testing. The drag accelerometer (numbered 3 ) is fixed to the model along the axis as shown in figure 5. The front lift and aft lift accelerometers are fixed to the metallic arms attached to the outer rings as shown in figure 5. During short test times of $800 \mu \mathrm{s}$, the model along with the accelerometers moves as a free body and the resulting accelerations are measured from the output of the accelerometers. Finite element modelling has been exhaustively used in the design of the accelerometer force balance system. Selection of rubber bushes with appropriate material properties such as Young's modulus and the stiffness determine the extent to which a sufficiently soft suspension system can be assumed. Suitable rubber bushes that justify the free-floating condition are chosen after carrying out detailed parametric studies and using FEM with a realistic model-balance system. The calibration of accelerometer balance system has been carried out with conventional drop-weight method (Reddy 1985) and also using standard accelerometer kit. The details of the calibration method for the balance system are discussed in Sahoo et al (2003). Although the original concept and the relevant theory of the accelerometer force balance was proposed before earlier (Vidal 1956), there were no further efforts to carry out an elaborate structural analysis of the complete system integrated with the test model or understand the effect of rubber characteristics on the measured acceleration history. Some of the salient features of the FEM modelling of the accelerometer force balance system carried out recently are presented below.

\subsection{Finite element modeling (FEM) and analysis of the model}

In the present work, the $60^{\circ}$ apex-angle blunt nose cone model at $0^{\circ}$ angle of attack is considered for the analysis. The accelerometers are treated as point sources at their bases with negligible mass compared to the model mass. Since the model has rotational symmetry about the major axis (Z-axis), an axi-symmetric FE model is considered. The FE model consists of 1308 2D 4-node quadrilateral axi-symmetric elements and the typical FEM mesh is shown in figure 6. Here, adequate fine mesh is essential to match the wavelength of the stress wave scattering inside the model. In this analysis, we evaluate only the axial force acting at the point where the drag accelerometer is located, as shown in figure 6. Displacements at the nodes along the bases of the rubber bushes are restrained. To start the simulations we 
assume that the hypersonic flow impinging on the model nose produces a single-step pressure loading at a particular point on the nose surface followed by steady amplitude till the end of the observation window. However, such a step pressure is experienced at different points away from the nose tip at different times. Corresponding time lags are computed assuming freestream velocity in front of the nose surface. Also, the pressure amplitude varies at points with different radii of revolutions $(R)$ and is computed from Newtonian flow over a curved surface (Anderson 1989). Under the distributed dynamic pressure history preprocessed this way, linear transient dynamic analysis with uniform time steps of $0 \cdot 1 \mu \mathrm{s}$ is performed using NISA software module. The results of FEM simulations for various rubber materials show that during the experimental test flow duration of $800 \mu \mathrm{s}$, the percentage drop in acceleration is almost negligible while using standard neoprene type rubber $(E=3 \mathrm{MPa})$. Frequency domain filtering is employed to include the effect of accelerometer bandwidth $(10 \mathrm{kHz})$ in the simulations. Figure 7 shows the experimentally recorded signal from the drag accelerometer along with the FEM simulated acceleration time history. The agreement of the acceleration levels from the drag accelerometer during the steady state shock tunnel flow is very good.

\subsection{Platinum thin-film sensors and measurement methodology}

Platinum thin-film sensors can be deposited on the Macor substrate using either hand painting or vacuum sputtering. It is very essential to ultrasonically clean the Macor substrate before we hand paint the sensors to ensure good adhesive characteristics of the film. In the present experiments the platinum sensors are hand painted on Macor using platinum 05-X metalloorganic paint (M/s Englehard-Clal, UK). The passive sensors are energized through constant current source $(\sim 20 \mathrm{~mA})$ and the gauge output is recorded using a PC-based data acquisition system. The initial resistance of all the platinum gauges is maintained at around $50 \Omega$. The change in resistance of the gauge due to the change in temperature gives a change in voltage across the gauge with respect to time, which corresponds to the temperature time history at the gauge location on the model surface. These temperature-time history signals are then numerically integrated (Cook \& Felderman 1966; Jagadeesh 1997) in order to get the convective surface heat transfer rates.

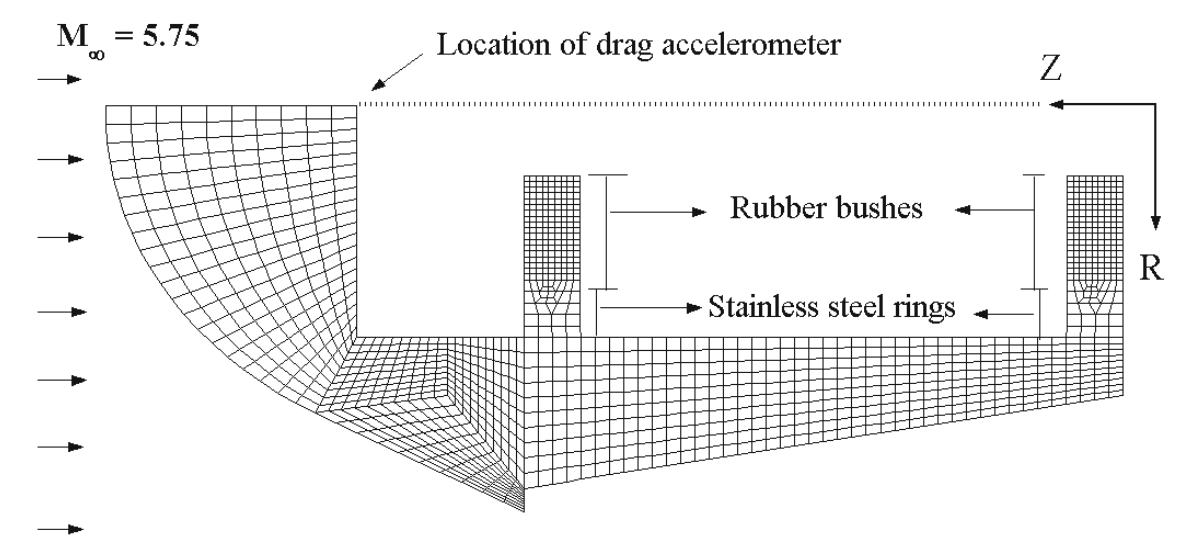

Figure 6. Axi-symmetric mesh used for finite element modelling of the $60^{\circ}$ apex-angle blunt cone model with internally mounted accelerometer balance system. 


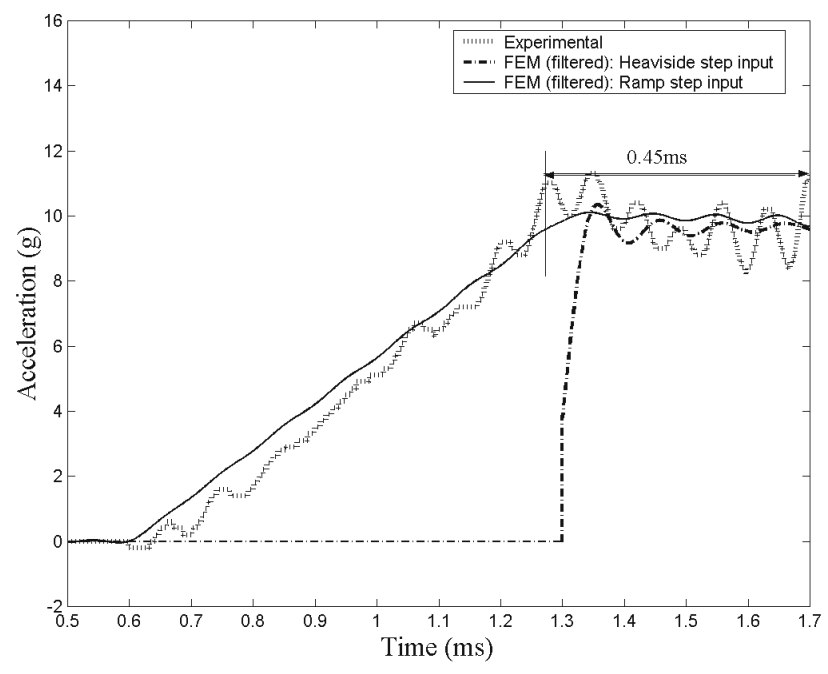

Figure 7. Recorded acceleration time history from the drag accelerometer along with the simulated acceleration time history using FEM.

\section{Results and discussions}

The $60^{\circ}$ apex-angle blunt cone model fitted with an accelerometer balance system and platinum thin-film sensors are tested at three conditions in the HST2 shock tunnel at various angles of attack with air as test gas. The convective surface heating rates and aerodynamic drag are measured simultaneously over the test model using platinum thin-film gauges and the accelerometer balance system respectively. In the present experimental setup, the test section sizing does not allow mounting the model and permanent Pitot probes simultaneously. Hence, prior to actual testing of the model in the tunnel, the freestream Pitot pressures are measured for three different stagnation enthalpy conditions (figure 8). A typical pressure history along

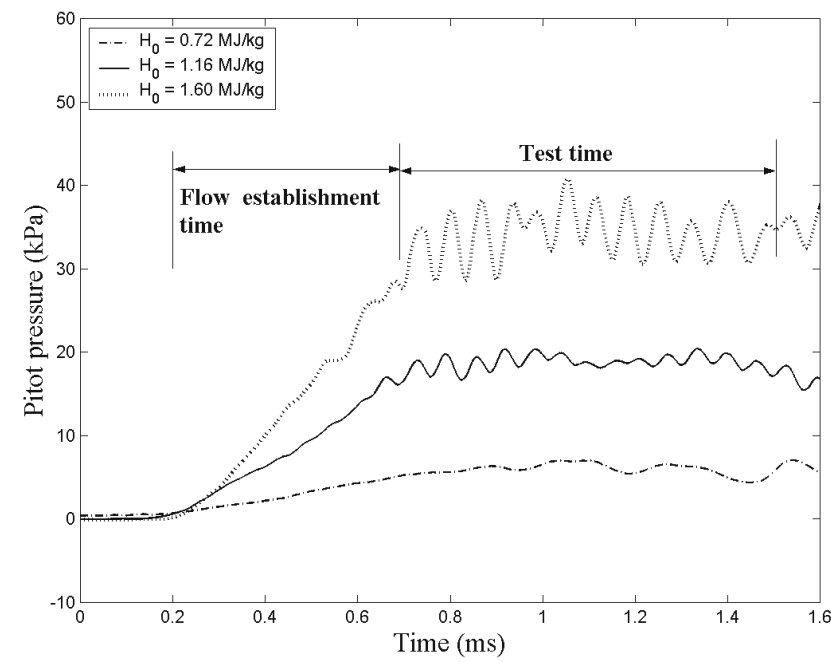

Figure 8. Typical Pitot pressure signals in the test section of HST2 shock tunnel for different enthalpies. 


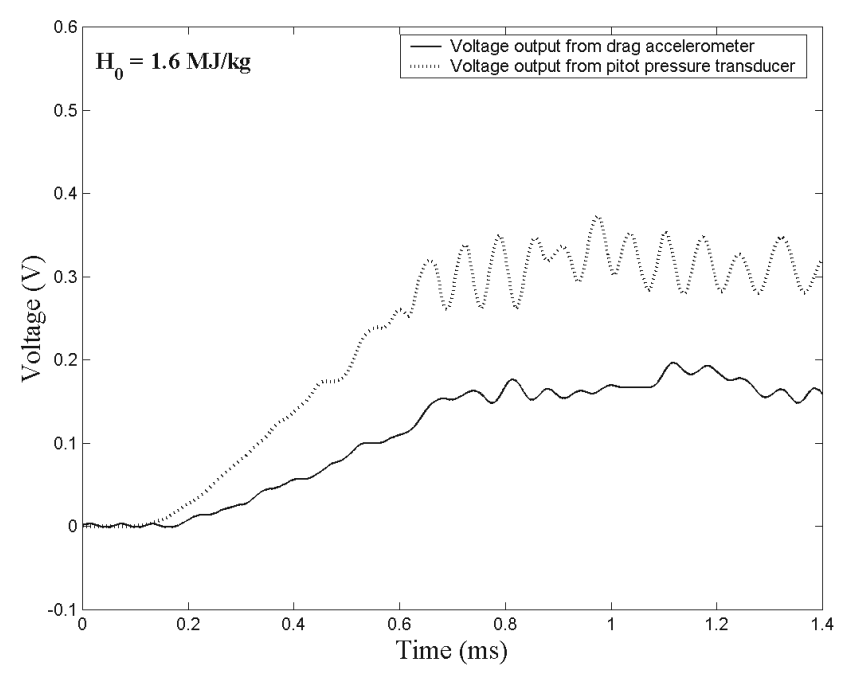

Figure 9. Typical Pitot pressure signal in the test section of the HST2 shock tunnel along with the drag accelerometer output.

with drag signal inferred from the drag accelerometer is shown in figure 9 for the case with stagnation enthalpy of $1.6 \mathrm{MJ} / \mathrm{kg}$. These signals indicate an initial ramp-like rise in voltage output for about $450 \mu$ s followed by steady state voltage prevailing for about $800 \mu$ s. Hence, all the experimental data are deduced by averaging results during the steady flow duration of $800 \mu \mathrm{s}$. In addition, the viscous interaction parameter has been estimated for various enthalpy conditions. For all the test conditions, the interaction parameter falls in the range $0 \cdot 13-0 \cdot 17$ that necessarily implies a region of weak interaction.

\subsection{Aerodynamic drag around a blunt cone}

The axial force $\left(C_{t}\right)$ is calculated from the measured acceleration from the drag accelerometer using the equation,

$$
C_{t}=m \xi
$$

where $m$ is the mass of the model $(=0.33 \mathrm{~kg})$ and $\xi$ is the measured acceleration from the drag accelerometer. The aerodynamic drag coefficient $\left(C_{d}\right)$ is also obtained from the measured accelerometer signals for the test model at various angles of attack $(\alpha)$ using the relation,

$$
C_{d}=\left(C_{t} \cos \alpha\right) /\left\{\left((\gamma / 2) P_{\infty} M_{\infty}^{2}\right)\left((\pi / 4) D_{b}^{2}\right)\right\},
$$

where $\gamma$ is the specific heat ratio ( $=1.4$ for air), $P_{\infty}$ is the freestream static pressure, $\mathbf{M}_{\infty}$ is the freestream Mach number and $D_{b}$ is the base diameter of the model $(=70 \mathrm{~mm})$,.

Theoretical values of aerodynamic force coefficients for the $60^{\circ}$ apex-angle blunt cone at different angles of attack are estimated using the modified Newtonian theory (Truitt 1959) to take into account the centrifugal force effects over the hemispherical nose portion of the blunt cone. In Newtonian flow, it is assumed that the gas stream maintains its speed and direction unchanged until it strikes the solid surface exposed to the flow, wherein it loses to the body the component of momentum normal to the surface and moves along the surface 
with the tangential component of the momentum unchanged. This Newtonian approximation does not specify the pressure on the surfaces that are not seen by the flow. So, in the present analysis, the Newtonian approximation is suitably modified by introducing a 'normalized factor'. The model used for the experiments in this case has a spherical nose blunt cone with a conical flare (included angle of $60^{\circ}$ ) followed by a stepped after-body attached to the cone shown in figure 5. A simplified figure used for calculating theoretical values of aerodynamic drag coefficient is given in figure 10. In this case, the aerodynamic force coefficients are calculated individually and then summed up to get the resultant force coefficients. A more elaborate analysis has been given by Sahoo (2003). However, for the sake of better readability, authors discuss this briefly, addressing the few important points for individual component.

Hemispherical nose cap: The drag coefficient $C_{d n}$ and the lift coefficient $C_{\mathrm{ln}}$ for the nose cap are estimated based on figures 11 and 12 respectively. From figure 11, the value of $C_{d n} \approx 0.75$ for a hemispherical nose cap of any diameter up to an angle of attack of $30^{\circ}$ and the value of $C_{\mathrm{ln}} \approx 0$ for any hemispherical nose cap up to $30^{\circ}$ angle of attack (figure 12). These $C_{d n}$ and $C_{\mathrm{ln}}$ values are normalized based on the blunt cone base diameter using a normalizing factor defined by,

$$
N F S=\left(D_{n} / D_{b}\right)^{2},
$$

with $D_{n}$ being the projected model nose diameter. Normalized drag and lift coefficients for the nose cap are then obtained from the following equations:

$$
\begin{aligned}
& C_{d n n}=N F S \times C_{d n}, \\
& C_{\ln n}=N F S \times C_{\ln } .
\end{aligned}
$$

Cone frustum: The following equations (Truitt 1959) are used to deduce the drag and lift coefficients $C_{c c f}$ and $C_{n c f}$ for the cone frustum portion of the model (figure 10).

$$
\begin{aligned}
& C_{c c f}=\left[\left(2 \sin ^{2} \delta_{V}\right)+\left(\sin ^{2} \alpha\right)\left(1-3 \sin ^{2} \delta_{V}\right)\right]\left\{\left(D_{b} / D_{b}^{\prime}\right)^{2}-1\right\}, \\
& C_{n c f}=\left(\cos ^{2} \delta_{V} \sin 2 \alpha\right)\left\{\left(D_{b} D_{b}^{\prime}\right)^{2}-1\right\} .
\end{aligned}
$$

Normalizing factor for the cone frustum,

$$
\mathrm{NFCF}=\left(D_{b} / D_{b}^{\prime}\right)^{2},
$$

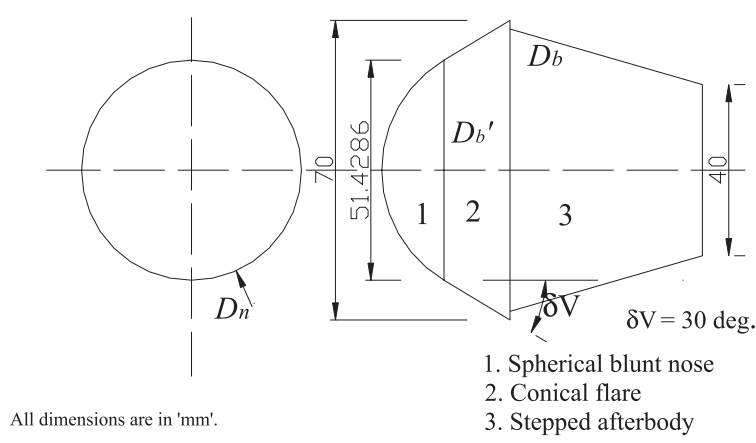

Figure 10. Some of the blunt cone dimensions used in theoretical estimation of aerodynamic force coefficients based on modified Newtonian theory. 


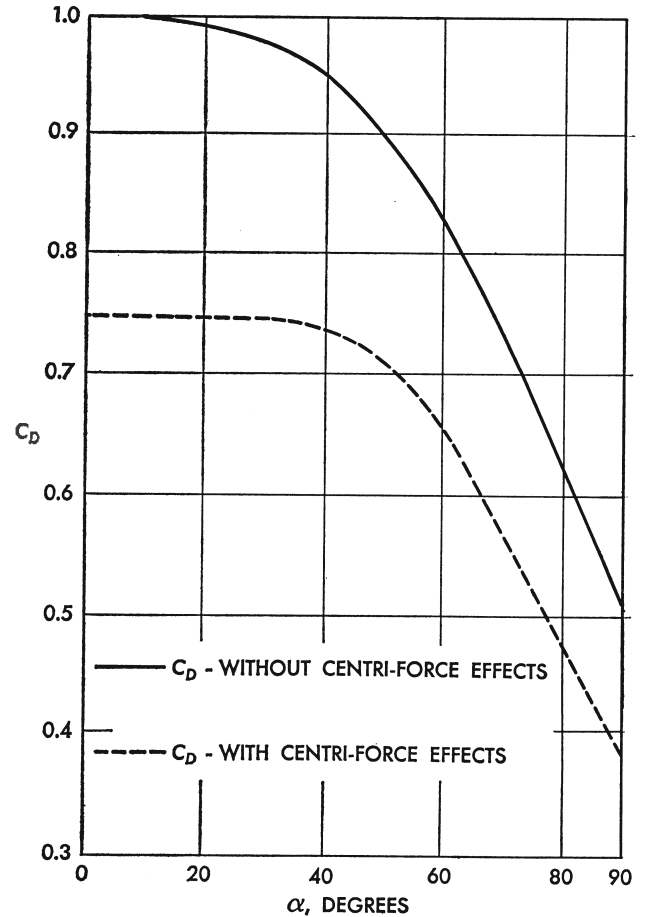

Figure 11. Variation of drag coefficient for a hemispherical nose based on modified Newtonian theory (Truitt 1959).

where $D_{b}^{\prime}$ and $D_{b}$ are the smaller and bigger diameters of the cone-frustum with semi-apex angle of $\delta_{V}$, and $\alpha$ is the angle of attack. Normalized axial force $\left(C_{c c f n}\right)$, normal force $\left(C_{n c f n}\right)$, drag $\left(C_{d c f n}\right)$ and lift $\left(C_{l c f n}\right)$ coefficients for the cone frustum are then obtained from the following equations:

$$
\begin{aligned}
C_{c c f n} & =C_{c c f} \times \mathrm{NFCF}, \\
C_{n c f n} & =C_{n c f} \times \mathrm{NFCF}, \\
C_{d c f n} & =C_{c c f n} \cos \alpha+C_{n c f n} \sin \alpha, \\
C_{l c f n} & =C_{n c f n} \cos \alpha-C_{c c f n} \sin \alpha .
\end{aligned}
$$

Finally, drag and lift coefficients for the blunt nosed cone are obtained from the following equations:

$$
\begin{aligned}
C_{d} & =C_{d c f n}+C_{d n n}, \\
C_{l} & =C_{l c f n}+C_{\ln n} .
\end{aligned}
$$

Comparison of measured aerodynamic drag coefficient on the blunt cone at various angles of incidence at Mach 5.75 along with the theoretical trend based on modified Newtonian approximation is shown in figure 13. An increasing trend with increase in angle of attack is noticed both in theoretical trend and in the measurements. It is seen that the agreement is reasonably good (within $\pm 6 \%$ ) between theory and experiment for various angles of attack (up to $12^{\circ}$ ) and at three different running conditions (in terms of stagnation enthalpy) in the shock tunnel. 


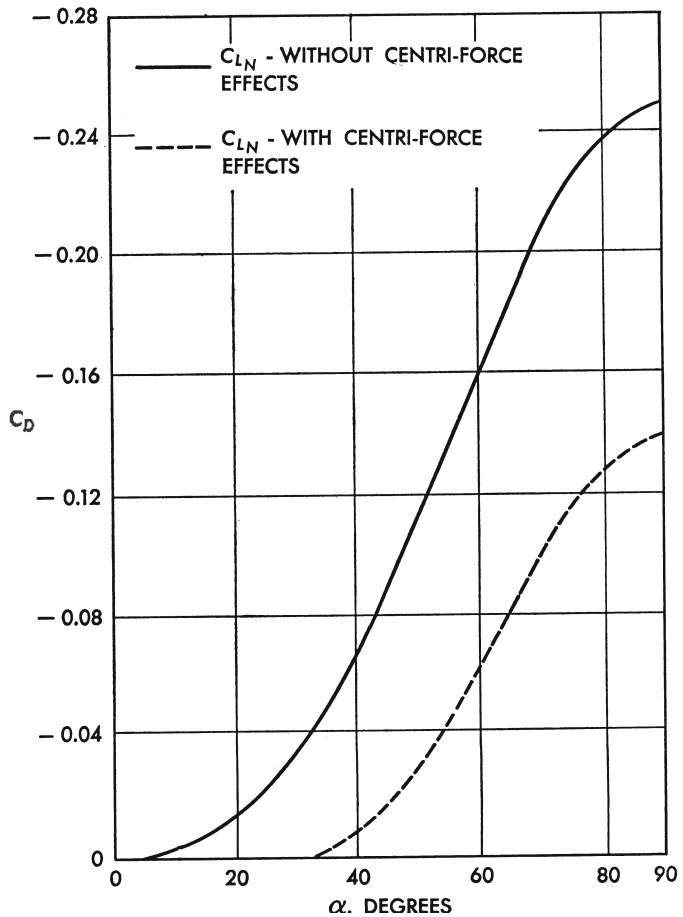

Figure 12. Variation of lift coefficient for a hemispherical nose based on modified Newtonian theory (Truitt 1959).

\subsection{Surface convective heat transfer measurements on a blunt cone}

Convective fore-body surface heat transfer rates $\left(q_{t}\right)$ measured at $0^{\circ}$ angle of incidence at different locations on the $60^{\circ}$ apex-angle blunt cone model are expressed in terms of ratio of

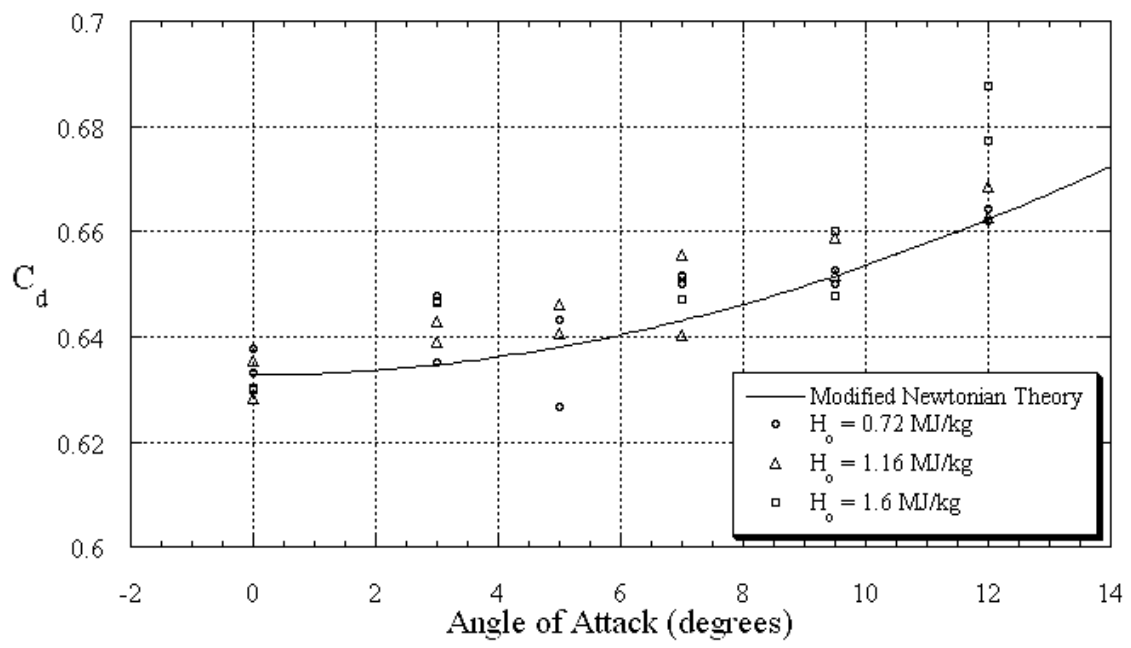

Figure 13. Variation of drag coefficient for the $60^{\circ}$ blunt cone model for various angles of attack at Mach 5.75. 
arc length on the cone surface $(s)$ from geometric stagnation point of zero incidence to the nose radius $\left(R_{n}\right)$. The negative values of $\left(s / R_{n}\right)$ correspond to the windward side and positive values correspond to the leeward side when the model is kept at positive angles of attack. These heat transfer rates at different locations are normalized with the stagnation point heat transfer rates based on the Fay-Riddell expression (Fay \& Riddell 1958) for stagnation point heat transfer rate for blunt bodies, as given below.

$$
Q_{o}=0.763 \operatorname{Pr}^{-0 \cdot 6}\left(\rho_{e} \mu_{e}\right)^{0.5}\left(\mathrm{~d} u_{e} / \mathrm{d} S\right)^{0 \cdot 5}\left[C_{p}\left(T_{o}-T_{w}\right)\right]
$$

where $\left(\mathrm{d} u_{e} / \mathrm{d} S\right)$ is the velocity gradient parameter (Anderson 1989); for the spherical nose portion, it is given by:

$$
\left(\mathrm{d} u_{e} / \mathrm{d} S\right)=(1 / \operatorname{Re})\left\{2\left(p_{e}-p_{\infty}\right) / \rho_{e}\right\}^{1 / 2},
$$

Pr is the Prandtl number ( $=0.71$ for air), $C_{p}$ is the specific heat capacity at constant pressure ( $=1.005 \mathrm{~kJ} / \mathrm{kg} . \mathrm{K}$ for air), $T_{0}$ is the freestream total temperature, $T_{w}$ is the wall temperature $(=300 \mathrm{~K})$, and $\mathrm{Re}$ is the plan form exposed nose radius of the model for flow and $p_{e}, \rho_{e}, \mu_{e}$ are the static pressure, static density and dynamic viscosity respectively, at the edge of the boundary layer. The conditions at the edge of the boundary layer are obtained by assuming the normal shock relations at the stagnation point and the dynamic viscosity at the edge of the boundary layer is calculated from Sutherland's law (Anderson 1989). The non-dimensional measured heat transfer rates are shown in figure 14 for various enthalpies at $0^{\circ}$ angle of attack. The heat transfer measurements have been expressed in terms of correslated Stanton number $\left(\mathrm{St}_{r}\right)$. This approach is based on the work carried out by Olivier \& Gronig (1995). The heat transfer rate as expressed in terms of Stanton number $(\mathrm{St})$ and correlated Stanton number $\left(\mathrm{St}_{r}\right)$ are,

$$
\begin{aligned}
\mathrm{St} & =q_{t} /\left\{\rho_{\infty} V_{\infty}\left[C_{p}\left(T_{o}-T_{w}\right)\right]\right\} \\
\mathrm{St}_{r} & =\operatorname{St}\left(\rho_{e} / \rho_{\infty}\right)^{2 / 3} /\left\{M_{\infty}\left[C^{*} / \operatorname{Re}_{\infty}\right]^{1 / 2}\right\}
\end{aligned}
$$

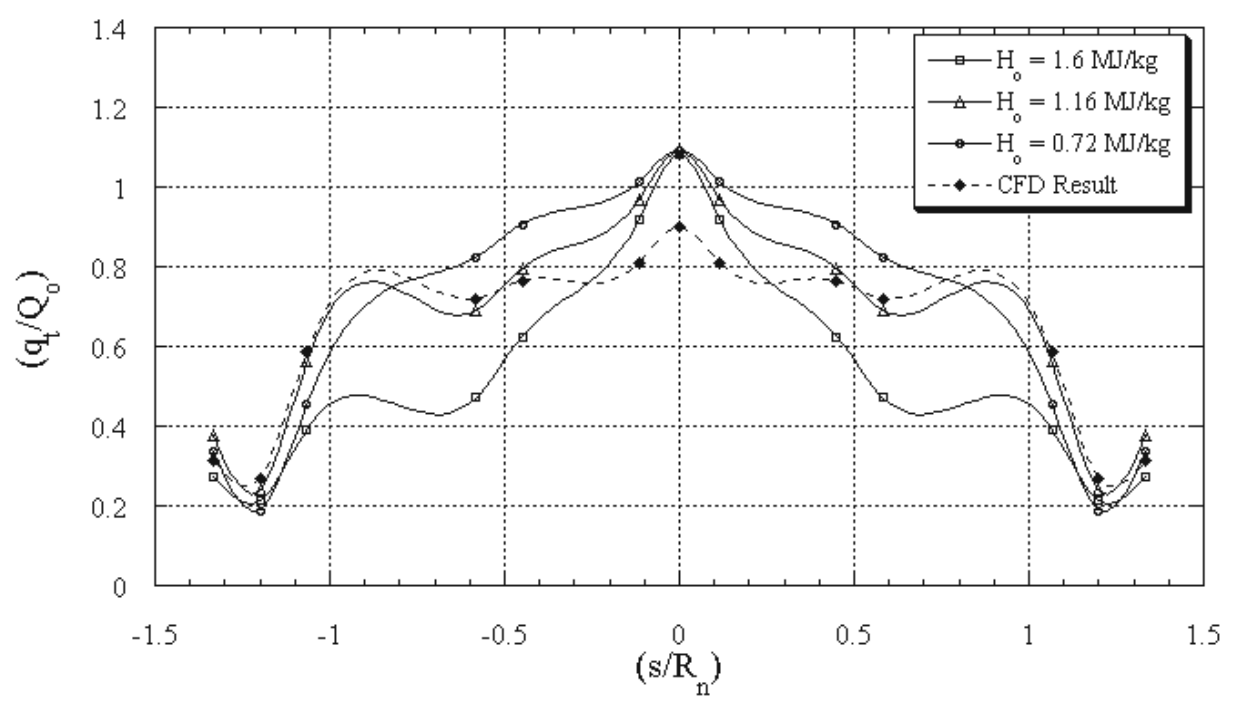

Figure 14. Variation of normalized heat transfer rates over the surface of the $60^{\circ}$ apex-angle blunt cone model at $0^{\circ}$ angle of attack for different stagnation enthalpies. 


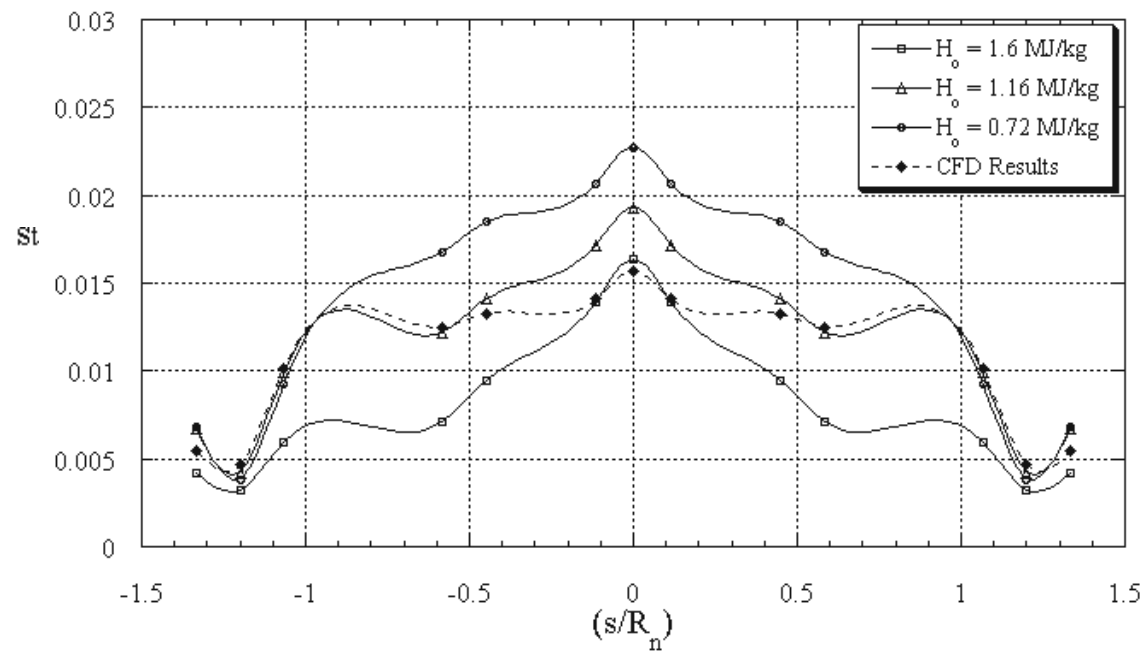

Figure 15. Variation of Stanton number over the surface of the $60^{\circ}$ apex-angle blunt cone model at $0^{\circ}$ angle of attack for different stagnation enthalpies.

where $V_{\infty}$ is freestream velocity and $\rho_{\infty}$ is freestream density. The density ratio in (24) is attributed to bluntness effects that depend on model geometry and flow conditions. The Chapman-Rubesin factor,

$$
C^{*}=\mu^{*} T_{\infty} / \mu_{\infty} T^{*},
$$

is calculated at the reference temperature $T^{*}$ defined by

$$
T^{*}=\left(T_{e} / 6\right)\left(1+3\left(T_{w} / T_{e}\right)\right)
$$

where, $\mu^{*}, \mu_{\infty}$ are the reference dynamic viscosity and freestream viscosity calculated at the reference temperature $T^{*}$ and freestream temperature $T_{\infty}$ respectively, using Sutherland's law. These results for Stanton number and correlated Stanton number are shown in figures 15 and 16. The results at $0^{\circ}$ angle of attack indicate that the maximum surface heat transfer rate occurs at the stagnation point of the model where the Stanton number $(\mathrm{St})$ and the correlated Stanton number $\left(\mathrm{St}_{r}\right)$ are maximum. This is essentially due to the large kinetic energy dissipation of the hypersonic flow in the thin shock layer. Farther from the stagnation zone, the heat transfer decreases gradually along the conical portion of the model. However, the pattern of heating rate distribution is symmetrical on both sides of the fore-body of the cone. The following significant inferences are drawn from the measured heat transfer data at $0^{\circ}$ angle of attack;

- Surface heating rates in the stagnation zone of the blunt cone are 7 times higher when the stagnation enthalpy $\left(H_{0}\right)$ is almost doubled. Typically, at $H_{0}=0.72 \mathrm{MJ} / \mathrm{kg}$, the measured heat transfer rate at the stagnation point is $\sim 6.7 \mathrm{~W} / \mathrm{cm}^{2}$, whereas the heating rate increases to $\sim 23.5 \mathrm{~W} / \mathrm{cm}^{2}$ at $H_{0}=1.16 \mathrm{MJ} / \mathrm{kg}$ and $\sim 48.4 \mathrm{~W} / \mathrm{cm}^{2}$ at $H_{0}=1.6 \mathrm{MJ} / \mathrm{kg}$.

- Corner heating increases by $\sim 20-30 \%$ of the stagnation point heat transfer rates at all enthalpy conditions (figures 11-13).

Normalized heating rates $\left(q_{t} / Q_{0}\right)$, local Stanton numbers (St) and correlated Stanton numbers $\left(\mathrm{St}_{r}\right)$ at different locations are measured at various angles of attack with $H_{o}=1 \cdot 16 \mathrm{MJ} / \mathrm{kg}$. 


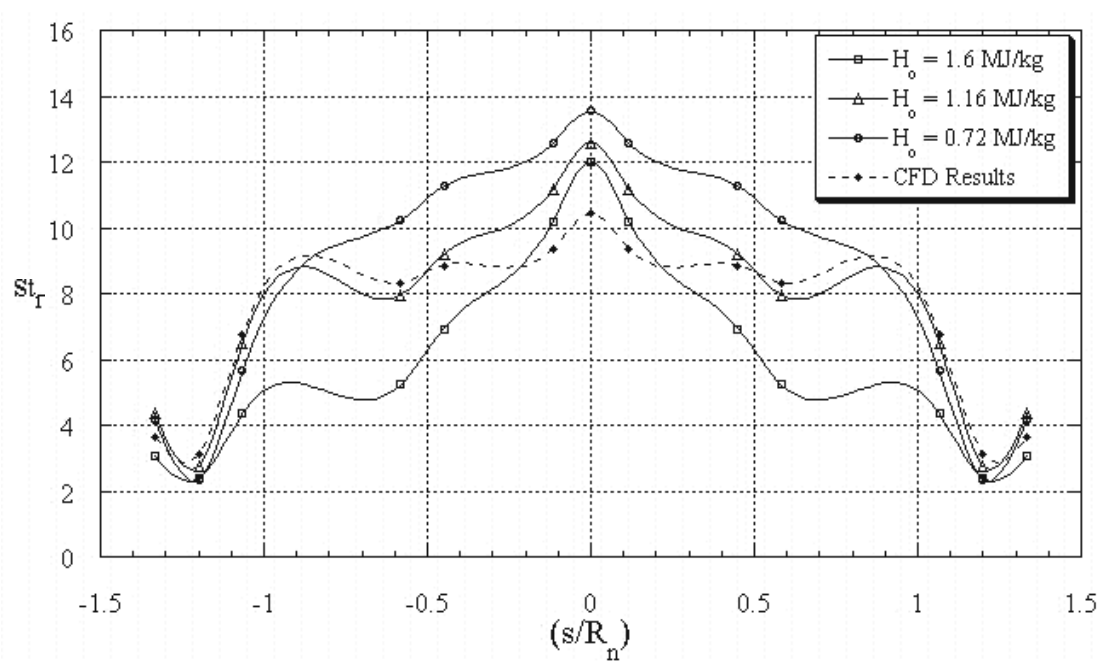

Figure 16. Variation of correlated Stanton number over the surface of the $60^{\circ}$ apex-angle blunt cone model at $0^{\circ}$ angle of attack for different stagnation enthalpies.

The results are shown in figures 17-19. These figures show an increase in heat transfer rates with angles of incidence in the windward side, whereas considerable reduction in heat transfer rates is observed on the leeward side of the model. Also, the stagnation point shifts towards the windward side of the model with increase in the angle of attack and lower values of heat transfer rates are observed at the location $\left[\left(s / R_{n}\right)=0\right]$. Unlike the symmetrical heating distributions observed at $0^{\circ}$ angle of incidence, the flow field features are completely different at angles of incidence. From the measured heat transfer data presented in figures 17-19, we observe the following.

- The windward side heating increases with angles of incidence while considerable reduction in heating rate is observed on leeward side of the blunt cone.

- The location of maximum heat transfer on the surface shifts towards the windward side of the model with increase in angle of attack while lower heating rates are observed at the nose of the model. This demands the presence of a thermal protection system not only at the nose but also at other parts of the surface of the re-entry vehicle at angle of attack.

- Corner heating increases with the angles of attack and at $12^{\circ}$ forms a considerable fraction (around 70\%) of the maximum heat measured on the cone surface as reported previously (Reddy 1980; Stewart \& Chen 1994; Hollis \& Perkins 1996).

- Except at $12^{\circ}$ angle of attack, the heat transfer measurements irrespective of angle of incidence correlate very well when expressed in terms of $\mathrm{St}_{r}$.

\subsection{Numerical simulation and comparison with experiments}

The flow fields around the test model are computed numerically using a commercial threedimensional N-S code called CFX-TASC flow for an axi-symmetric case with appropriate boundary conditions such as free-stream velocity, static temperature and static pressure based 


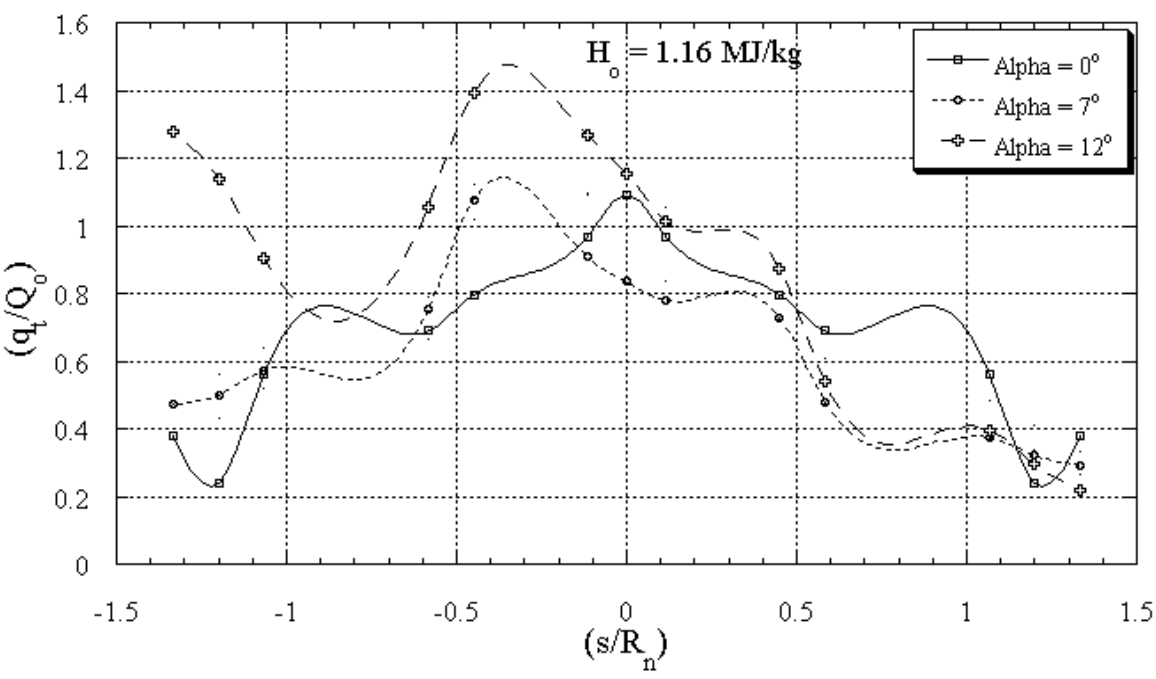

Figure 17. Variation of normalized heat transfer rates over the surface of the $60^{\circ}$ apex-angle blunt cone model at various angles of attack $\left(H_{0}=1 \cdot 16 \mathrm{MJ} / \mathrm{kg}\right)$.

on the experiments in HST2 for the stagnation enthalpy of $1 \cdot 16 \mathrm{MJ} / \mathrm{kg}$. The details of CFD computations using CFX-TASC flow for various blunt body configurations have been highlighted by Jagadeesh (1997) and Viren (2003). The multi-block, body-fitted grid used for the computations has a total number of around 25836 nodes (grid points). The grid cell height near the wall is around $8 \times 10^{-4} \mathrm{~m}$. The various boundary conditions used in the study are as follows:

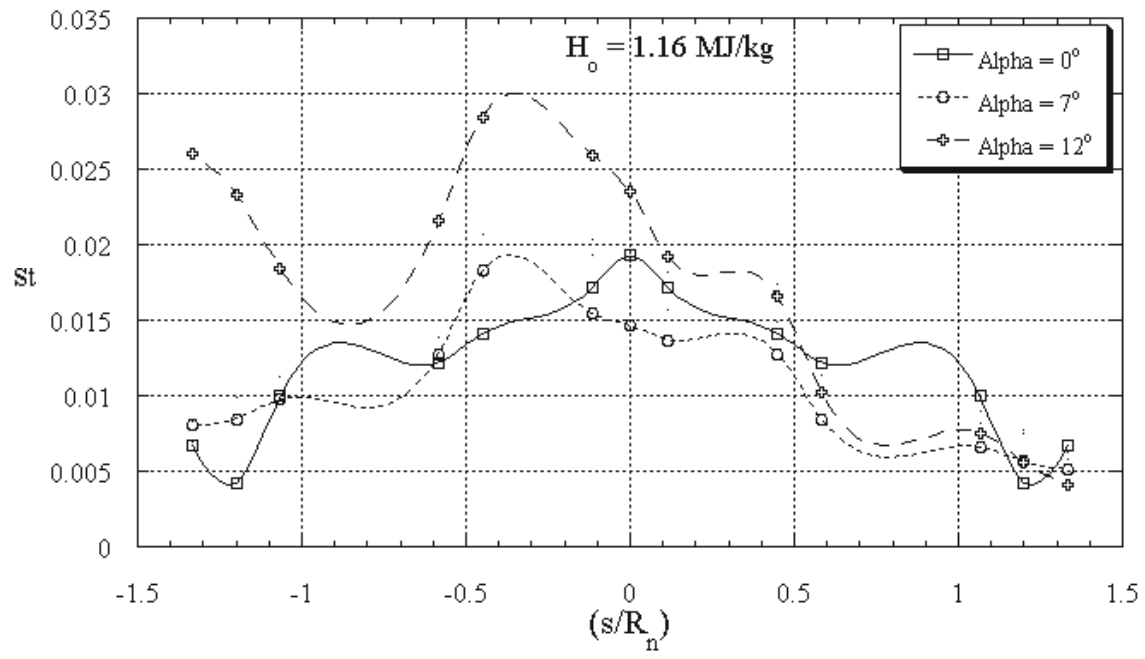

Figure 18. Variation of Stanton number over the surface of the $60^{\circ}$ apex-angle blunt cone model at various angles of attack $\left(H_{0}=1 \cdot 16 \mathrm{MJ} / \mathrm{kg}\right)$. 


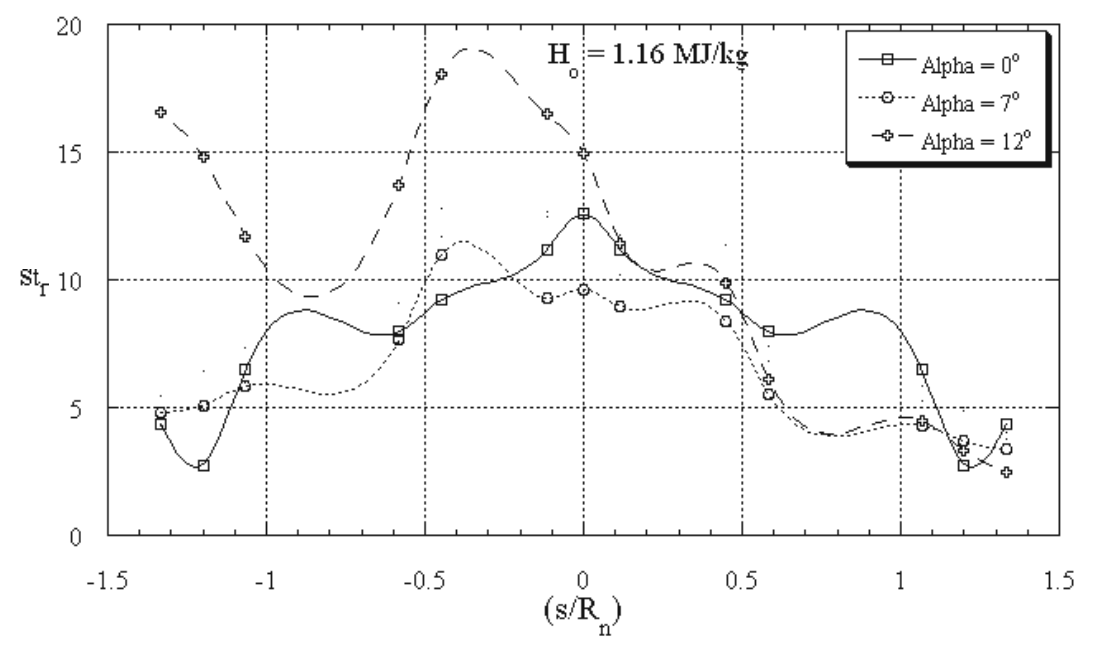

Figure 19. Variation of correlated Stanton number over the surface of the $60 \circ$ apex-angle blunt cone model at various angles of attack $\left(H_{0}=1 \cdot 16 \mathrm{MJ} / \mathrm{kg}\right)$.

Inlet: At this boundary of the computational domain, velocity, static pressure and static temperature of the flow have been specified. Typical values used here are velocity $=1365 \mathrm{~m} / \mathrm{s}$, pressure $=450 \mathrm{~N} / \mathrm{m}^{2}$ and temperature $=140 \mathrm{~K}$. These are the flow properties obtained at the inlet of the test section (freestream) in the shock tunnel for an enthalpy level of $1.16 \mathrm{MJ} / \mathrm{kg}$ (see table 1).

Outlet: At the outlet of the computational domain, all variables are extrapolated from the interior domain.

Wall: The wall boundary condition is used at the blunt cone model surfaces. The fluid at these surfaces is assumed to have a no-slip condition. A constant temperature of $300 \mathrm{~K}$ is specified at the walls.

Symmetry: Other bounds of the computational domain, excluding inlet and outlet, are specified as symmetry planes. The fluid velocity is assumed to be tangential at these symmetry planes.

An upwind differencing scheme has been used for the computations with a local time step of 0.9. The target residuals to terminate the simulation have been set at $1 \times 10^{-4}$. About 1500 iterations (time steps) have been used for the convergence. Approximately 3 hours of CPU time were required for the simulation on an Intel Pentium 4, $1.4 \mathrm{GHz}$ processor. The program is run on a Windows NT platform. A full viscous solution is obtained from the CFD computation. It is found that the skin friction contributes only $2 \%$ of the total drag. So the drag coefficient over the test model at $0^{\circ}$ angle of attack is computed by integrating the surface pressure over the fore-body part of the blunt cone as shown in figure 20 and is $=0.6885$. The convective surface heat transfer rates over the test model surface at various locations are also computed from the CFD code. The measured values and the computed values of the drag coefficient $\left(C_{d}\right)$ for the blunt cone at various enthalpy conditions at $0^{\circ}$ angle of attack are given in table 2, along with the measurement uncertainties. The theoretical estimate of $C_{d}$ based on modified Newtonian theory differs by about $1 \%$ compared to experimental values, while the axi-symmetric numerical computations over predict $C_{d}$ by $\sim 9 \%$. 


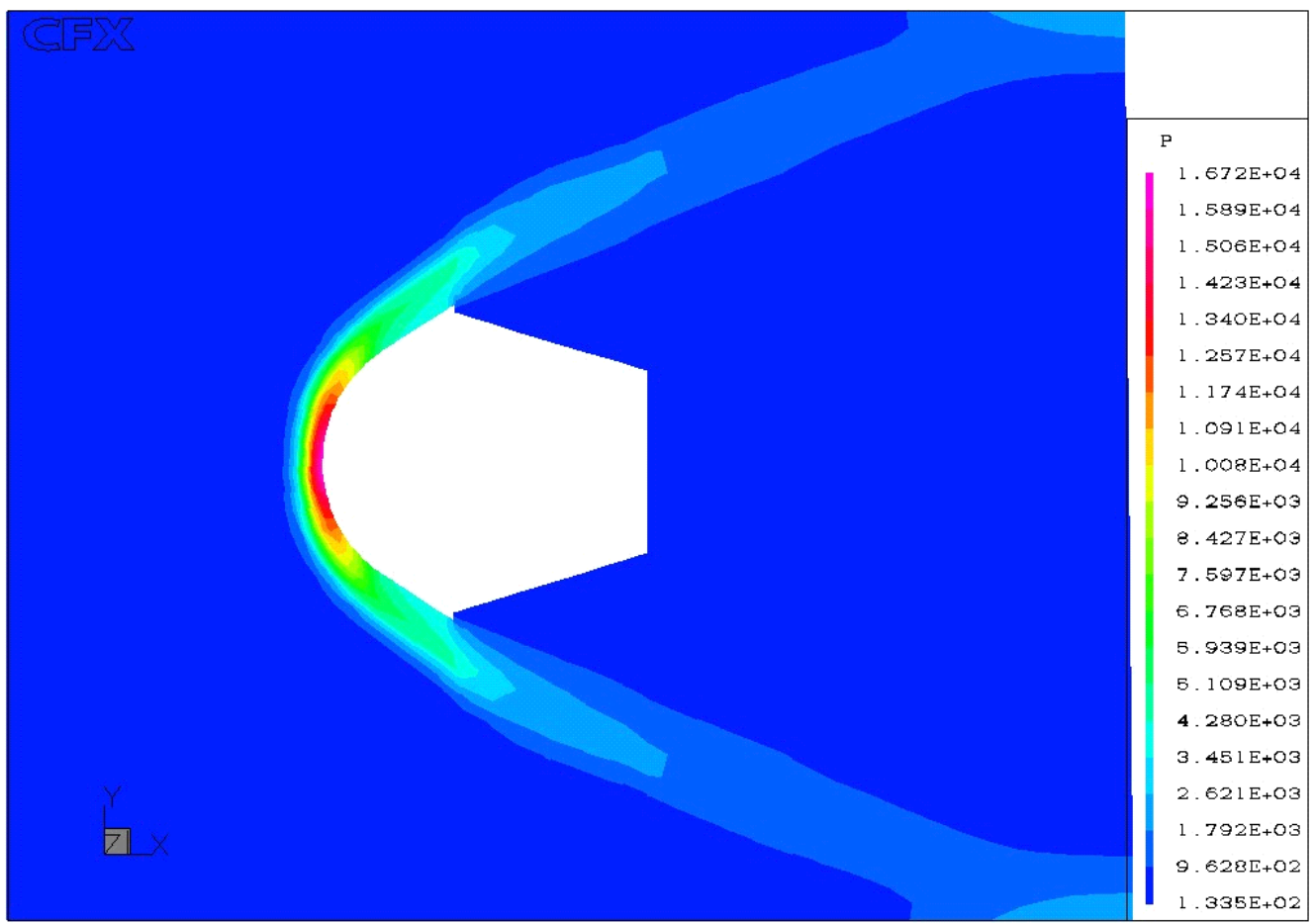

Figure 20. Numerically computed pressure distribution around the $60^{\circ}$ apex-angle blunt cone model flying at Mach 5.75.

Thus the agreement is reasonably good between theory and experiment for both lower and higher stagnation enthalpies. Table 3 compares the measured stagnation point heat transfer rates with the theoretical values. The comparisons are based on the normalized values of heat transfer rate, Stanton number and correlated Stanton number calculated using the FayRiddell expression. The experimental prediction is about $11 \%$ higher and the numerically computed results show $2 \%$ lower values for the heat transfer rates at the stagnation point of the model.

Table 2. Comparison of drag coefficients at $0^{\circ}$ angle of attack*

\begin{tabular}{ll}
\multicolumn{2}{c}{ All $H_{0}$ values in $\mathrm{MJ} / \mathrm{kg}$} \\
\hline & Drag coefficient, $C_{d}$ \\
\hline Modified newtonian theory & 0.6327 \\
CFD simulation at $H_{0}=1.16$ & 0.6885 \\
Experimental $H_{0}=0.72$ & $0.6378( \pm 8.5 \%)$ \\
$H_{0}=1.16$ & $0.6354( \pm 8.5 \%)$ \\
$H_{0}=1.60$ & $0.6301( \pm 8.5 \%)$ \\
\hline
\end{tabular}

*Numbers within parentheses indicate percentage of uncertainty. 
Table 3. Comparison of normalized heat transfer rate, Stanton number and reduced Stanton number at $0^{\circ}$ angle of attack* .

All $H_{0}$ values are in $\mathrm{MJ} / \mathrm{kg}$

\begin{tabular}{llcc}
\hline & \multicolumn{3}{c}{$60^{\circ}$ apex angle blunt nose cone model } \\
\cline { 2 - 4 } Experiment & $\left(q_{t} / Q_{o}\right)$ & \multicolumn{1}{c}{$\mathrm{St}$} & $\mathrm{St}_{\mathrm{r}}$ \\
\hline At $H_{o}=0.72$ & $1.1010( \pm 12 \%)$ & $0.02250( \pm 10 \cdot 8 \%)$ & $13.22( \pm 11 \%)$ \\
At $H_{o}=1.16$ & $1.0907( \pm 12 \%)$ & $0.01931( \pm 10 \cdot 8 \%)$ & $12.60( \pm 11 \%)$ \\
At $H_{o}=1.6$ & $1.1250( \pm 12 \%)$ & $0.01702( \pm 10 \cdot 8 \%)$ & $12.00( \pm 11 \%)$ \\
CFD simulation at $H_{o}=1.16$ & 0.9009 & 0.01598 & $10 \cdot 50$ \\
\hline
\end{tabular}

${ }^{*}$ Numbers within parentheses indicate percentage of uncertainty.

\subsection{Measurement uncertainties}

The uncertainties in the test flow conditions, drag and heating rate measurements have been estimated using sequential perturbation techniques (Srinivasa 1991; Mee 1993). The uncertainties associated with test flow conditions include contributions from uncertainties in shock tube filling conditions, shock speeds (inferred from platinum thin-film gauges) and measured outputs from the data acquisition system. Uncertainties in the flow conditions are shown in table 1. Uncertainties in the accelerometer sensitivities, setting of angle of attack, output signals from the data acquisition systems, restraint offered by the rubber bushes to the free flight of the model during test time and mass of the model are some of the factors that contribute to the uncertainties in $C_{d}$ (table 2). Based on the uncertainties associated with the gauge characteristics, data acquisition system, data reduction techniques and calibration, the measured values of heat transfer rates are believed to be accurate to $\pm 5 \%$ with helium as driver gas. Various factors such as uncertainty in angle of attack, misalignment of Macor inserts, discontinuity in substrate and model properties and departure from one-dimensional heat conduction during the run time contribute to the uncertainties in the measured Stanton number. Finally, the estimated uncertainties in the measured data are $\Delta C_{d}=0.085 C_{d}, \Delta q_{\infty}=0.064 q_{\infty}$ and $\Delta \mathrm{St}=0.085 \mathrm{St}$. All uncertainties are at $95 \%$ confidence interval levels.

\section{Conclusion}

Combined measurements of aerodynamic drag and convective surface heat transfer rates have been carried out for a $60^{\circ}$ apex-angle blunt cone model flying at Mach 5.75 in the HST2 shock tunnel at various angles of attack. An accelerometer-based three-component balance system is used to measure aerodynamic drag while platinum thin-film gauges are used for convective surface heat transfer rate over the test model. Finite element analysis of modelbalance assembly at $0^{\circ}$ angle of attack is carried out to choose appropriate rubber bushes for achieving free-floating model conditions in the test section. The theoretically estimated values of drag coefficient at $0^{\circ}$ angle of attack based on modified Newtonian theory differ by about $\pm 6 \%$ from the experimental values, while the axi-symmetric Navier-Stokes computations overpredict $C_{d}$ by $\pm 9 \%$. The experimental prediction of normalized heating rate is about $11 \%$ higher and the numerically computed results are about $2 \%$ lower at the stagnation point of the model at $0^{\circ}$ angle of attack. Experimental correlations in terms of reduced Stanton 
number is obtained for the range of enthalpies and angles of attack based on the measured surface heat transfer values. The simultaneous measurement of drag and convective surface heating rates at $0^{\circ}$ angle of attack compares very well with the theoretical estimates. This novel method of measuring both the aerodynamic data and the heat transfer data using the same model in shock tunnels is certainly cost effective. These data are expected to be very useful for validation of CFD codes used for numerical computation of hypersonic flow fields.

The support rendered by Dr Viren Menezes, and M/s K Nagashetty, Gangadhar, Kiran Suryavamshi and Vinayak Kulkarni during the course of this work is gratefully acknowledged

\section{References}

Abdel-Jawad M M, Mee D J, Morgan R G, Jacobs, P A, Philpot J A 2001 Transient force measurements at superorbital speeds. Proc. $23^{\text {rd }}$ Int. Symp. on Shock Waves (ed.) F K Lu, Fort Worth, TX, pp. 515521

Alan P, Kennith L G 1965 High-speed wind tunnel testing (New York: John Wiley \& Sons)

Anderson J D Jr 1989 Hypersonic and high temperature gas dynamics (Series in Aeronautical and Aerospace Engineering) (New York: McGraw-Hill)

Brian R H, John N P 1997 High enthalpy aerothermodynamics of a Mars entry vehicle Part 1: Experimental results, J. Spacecr. Rockets 34: 449-456

Cook W J, Felderman E J 1966 Reduction of data from thin film heat transfer gauge: A concise numerical technique. AIAA J. 4: 561-562

Fay J A, Riddell F R 1958 Theory of stagnation point heat transfer in dissociated air. J. Aeronaut. Sci. 25: $73-85$

Hollis B R 1995 User's manual for the one-dimensional hypersonic experimental aero thermodynamic (1DHEAT) data reduction code. NASA CR-4961

Hollis B R, Perkins J N 1996 High enthalpy and perfect gas heating measurements on a blunt cone. J. Spacecr. Rockets 33: 628-634

Jagadeesh G 1997 Experimental investigations of the flow-fields around large angle blunt cones flying at hypersonic Mach number. Ph D thesis, Department of Aerospace Engineering, Indian Institute of Science, Bangalore

Jagadeesh G, Reddy N M, Nagashetty K, Reddy, K P J 2000 Fore body convective hypersonic heat transfer measurements over large angle blunt cones. J. Spacecr. Rockets 37: 137-139

Jessen C, Gronig H 1989 A new principle for a short-duration six component balance. Exp. Fluids 8: 231-233

Joshi M V, Reddy N M 1986 Aerodynamic force measurements over missile configurations in IISc shock tunnel at $\mathrm{M}_{\infty}=5 \cdot 5$. Exp. Fluids 4: 338-340

Lee J Y, Lewis M J 1993 Numerical study of the flow establishment time in hypersonic shock tunnels. J Spacecr. Rockets 30: 152-163

Mee D J, Daniel W J T, Simmons J M 1996 Three-component force balance for flows of millisecond duration. AIAA J. 34: 590-595

Mee D J 1993 Uncertainties analysis of conditions in test section of the T4 shock tunnel, Research Report No: 4/93, Center for Hypersonics, University of Queensland, Australia

Naumann K W, Ende H, Mathieu G, George A 1993 Millisecond aerodynamic force measurement with side-jet model in ISL shock tunnel. AIAA J. 31: 1068-1074

Olivier H, Gronig H 1995 Hypersonic model testing in a shock tunnel. AIAA J. 33: 262-265

Peter F I, Donn B K 1987 High-speed aerodynamics of several blunt-cone configurations. J. Spacecr. Rockets 24: 127-132 
Raju C, Reddy N M 1990 Aerodynamic force measurements over missile configurations in IISc shock tunnel at $\mathrm{M}_{\infty}=3 \cdot 85$ and 9.15. Exp. Fluids 10: 75-77

Reddy N M 1980 Heating rate measurements over $30^{\circ}$ and $40^{\circ}$ (half-angle) blunt cones in air and helium in the Langley expansion tube facility. NASA TM-80207

Reddy N M 1985 Development of a three-component balance for use in a shock tunnel, High Enthalpy Aerodynamic Report No. 85 HEA 2 Serial No. 04, Department of Aerospace Engineering, Indian Institute of Science, Bangalore, India

Sahoo N, Mahapatra D R, Jagadeesh G, Gopalakrishnan S, Reddy K P J 2002 Aerodynamic force measurements on $60^{\circ}$ apex angle blunt cones flying at Mach 5.75 using a three-component accelerometer balance. AIAA Paper 2002-5204

Sahoo N, Mahapatra D R, Jagadeesh G, Gopalakrishnan S, Reddy K P J 2003 An accelerometer balance system for measurement of aerodynamic force coefficients over blunt bodies in a hypersonic shock tunnel. Meas. Sci. Technol. 14: 260-272

Sahoo N 2003 Simultaneous measurement of aerodynamic forces and convective surface heat transfer rates for large angle blunt cones in hypersonic shock tunnel, $\mathrm{Ph} \mathrm{D}$ thesis, Department of Aerospace Engineering, Indian Institute of Science, Bangalore, India.

Schultz D L, Jones T V 1973 Heat transfer measurements in short-duration hypersonic facilities. AGARDograph No. 165.

Srinivasa P 1991 Experimental investigations of hypersonic flow over a bulbous heat shield at Mach number 6. Ph D thesis, Department of Aerospace Engineering, Indian Institute of Science, Bangalore, India.

Stewart D A, Chen Y K 1994 Hypersonic convective heat transfer over $140^{\circ}$ blunt cones in different gases. J. Spacecr. Rockets 31: 735-743

Truitt R W 1959 Hypersonic aerodynamics (New York: Ronald Press)

Vidal R J 1956 Model instrumentation techniques for heat transfer and force measurements in a hypersonic shock tunnel. Cornell Aeronautical Laboratory Report, WADC TN 56-315

Viren M, Saravanan S, Jagadeesh G, Reddy K P J 2002 Aerodynamic drag reduction using aero-spikes for large angle blunt cone flying at hypersonic Mach number. AIAA Paper 2002-2709

Viren M 2003 Investigations of aero-spike induced flow field modifications around a large angle blunt cone flying at hypersonic Mach number. Ph D thesis, Department of Aerospace Engineering, Indian Institute of Science, Bangalore 